\title{
Mathematical modelling of concrete compressive strength with waste tire rubber as fine aggregate
}

\author{
B.W. Chong ${ }^{1 *}$, R. Othman ${ }^{1}$, P. J. Ramadhansyah², S. I. Doh² and Xiaofeng Li² \\ ${ }^{1}$ Faculty of Civil Engineering Technology, Universiti Malaysia Pahang, 26300, Gambang, Pahang, Malaysia \\ Phone: +6094246234; Fax: +609424222 \\ ${ }^{2}$ Department of Civil Engineering, College of Engineering, Universiti Malaysia Pahang, 26300, Gambang, Kuantan, Pahang, Malaysia
}

\begin{abstract}
With the increasing number of vehicle due to the boom of population and rapid modernisation, the management of waste tire is growing problem. Reusing grinded tire rubber in concrete is a green innovation which provide an outlet for reusing waste tire. While providing certain benefits to concrete, incorporation of tire rubber results in significant loss of concrete compressive strength which hinders the potential of rubberised concrete. This paper aims to develop mathematical models on the influence of tire rubber replacement on the compressive strength of concrete using design of experiment (DoE). 33 data sets are gathered from available literature on concrete with waste tire rubber as partial replacement of fine aggregate. Response surface methodology (RSM) model of rubberised concrete compressive strength shows great accuracy with coefficient of determination $\left(R^{2}\right)$ of 0.9923 and root-mean-square error (RMSE) of 2.368. Regression analysis on the strength index of rubberised concrete shows that rubberised concrete strength loss can be expressed in an exponential function of percentage of replacement. The strength loss is attributed to morphology of rubber particles and the weak bonds between rubber particles and cement paste. Hence, tire rubber replacement should be done sparingly with proper treatment and control to minimise concrete strength loss.
\end{abstract}

\section{ARTICLE HISTORY}

Received: $14^{\text {th }}$ Feb 2021

Revised: 26 $6^{\text {th }}$ July 2021

Accepted: $15^{\text {th }}$ Aug 2021

\section{KEYWORDS}

Concrete;

compressive strength;

waste tire rubber;

response surface

methodology;

regression.

\section{INTRODUCTION}

Management of waste tire is becoming a growing concern and posts a huge challenge to scientists and industries alike [1]. While Malaysia faces challenge in solid waste management, tire waste is a problem that affect nations across the entire globe [2]. United States has the world's highest waste tires generation at 270 million annually, followed by Japan with over 110 million waste tires for each year [3]. In India, millions of tons of waste tires are produced every year and around 60 percent of said waste are disposed from urban and rural areas [4]. Roughly 30,000,000 million waste tires are also produced in France per year [5]. Reusing of tire waste is a long-running initiative that aims to minimise tire waste that ends up in the landfill. In Malaysia, the generation of motorcar waste tire generated has increased to about 8 millions tonnes but about $60 \%$ of those waste has been disposed through questionable routes [6]. In general, Malaysia also faces challenges with solid waste management with an alarmingly low recycling rate [7]. At present, waste tire rubber is proposed to be reused as various industrial products [8] such as thermosetting resin [9]. The field of civil engineering has also performed studies on the possibility of reusing waste tire rubber as flexible pavement [4] and structural concrete [10]. Deshmukh \& Kshirsagar [11] utilised waste tire rubber in the production of flexible pavement and concluded that the tire rubber improves the stiffness of bitumen and results in pavement with longer road life. Bani-Hani \& Senouci [12] experimented with rubberised concrete in pedestrian block for its improved ductillity and energy absorption. Similarly, rubberised concrete was postulated to show potential as roadside barrier due to its enhanced ductility [13].

Despite its wide array of potential applications, one major challenge of waste tire rubber in concrete is the massive loss of strength incurred when tire rubber is used as partial replacement for fine aggregate. For example, Silva et al. [14] prepared a high strength concrete with silica fume which achieved a compressive strength of $97.4 \mathrm{MPa}$ at 28 days but a strength drop of more than $20 \%$ is observed when $7.5 \%$ of the fine aggregate is replaced by tire rubber. At $30 \%$ replacement, concrete losses over half of its compressive strength as compared to control. Azevedo et al. [15] experimented with high strength concrete with $75 \mathrm{MPa}$ but about a third of the strength is loss when fine aggregate is replaced by $5 \%$ waste tire rubber. While proper handling and treatment of rubber crumb minimises the weakness incur by the use of tire rubber [16], the weakening effect still poses a challenge to ensure effective and efficient applications of rubberised concrete. Moreover, the conventional solution to the challenge has been to prepare concrete with significant higher compressive strength to withstand the strength loss and ensure that the concrete is within the target strength. However, this method is not efficient and economic due to the cost of producing high-strength concrete. So far, a detailed mathematical study on the function of strength loss has not been studied.

Recently, Design of Experiment (DoE) techniques such as regression analysis and Response Surface Methodology (RSM) is being applied in the study of concrete material. Regression is a basic method to study the correlation between 
variables. RSM takes the analysis a step ahead by considering the first order, second order, and interaction effects between the variables in order to formulate a response surface which determines the optimum condition for the dependent variable. It can provide a mathematical solution to a problem, reduce the number of experimental trials, and save the cost and time of a study [17]. It has been applied to provide detailed analysis and accurate estimation in the studies of sustainable concrete with replacement materials. Busari [18] applied the RSM analysis to study the properties of concrete with metakaolin and to determine the optimum amount of metakaolin for maximum compressive strength. Rosa et al. [19] studied the influence of steel fibre on the fresh and hardened properties of concrete for construction applications. In certain cases, multiple DoE methodologies, including RSM was conducted in unision for the study of concrete with green replacement material [20].

In this study, mathematical model of rubberised concrete 28 days compressive strength is developed using RSM. The percentage of tire rubber replacement and the amount of each concrete constituents are taken as the variables to predict concrete strength. The efficacy of the model is accessed by the determination coefficient $\left(\mathrm{R}^{2}\right)$, root mean-square error (RMSE), and other supplementary figures from RSM model. The a-10 index is adopted to evaluate the fitting of the predicted data with respect to the experimental data. Strength index of rubberised concrete is computed and regression analysis is used to study the effect of tire rubber replacement on the 28 days strength of rubberised concrete.

\section{METHODS AND MATERIALS}

\section{Waste Tire Rubber}

Despite the loss of mechanical strength, incorporation of waste tire rubber into concrete yields many benefits such as better resistance to aggressive substance [21][22], improved freeze-thaw resistance [23], resistance to impact [24] and fatigue [25]. In this study, waste tire rubber in fine size such as $0.30 \mathrm{~mm}$ and $0.50 \mathrm{~mm}$ [26] is used in a literature. Other studies use tire rubber with particle size similar to sand, which ranges from maximum nominal size of 1.00mm [27], $2.40 \mathrm{~mm}$ [15], 4.00mm [13] and 4.80mm [14]. The physical properties of tire rubber are investigated in the literature and compiled in Table 1.

Table 1. Properties of waste tire rubber

\begin{tabular}{cccc}
\hline \multirow{2}{*}{ Properties } & \multicolumn{3}{c}{ Waste Tire Rubber } \\
\cline { 2 - 4 } & {$[14]$} & {$[26]$} & {$[28]$} \\
\hline Specific density $\left(\mathrm{g} / \mathrm{cm}^{3}\right)$ & 1.17 & $0.91-1.11$ & - \\
Specific gravity $\left(\mathrm{g} / \mathrm{cm}^{3}\right)$ & - & - & 0.54 \\
Bulk density $\left(\mathrm{g} / \mathrm{cm}^{3}\right)$ & 0.33 & - & - \\
Fineness modulus $(\%)$ & 3.49 & - & 2.36 \\
Water absorption $(\%)$ & - & $4.49-10.09$ & - \\
\hline
\end{tabular}

\section{Database}

Experimental data are gathered from literature on concrete with waste tire rubber as partial sand replacement as compiled on Table 2. A total of 33 data set are collected from five literatures in which the material used, mix composition and 28 days compressive strength are clearly specified. Literature on concrete with waste tire rubber and silica is included as there exist sufficient similar studies to include silica fume as a constituent of concrete. A total of seven inputs are chosen as the independent variables or predictors, namely tire rubber percentage, maximum size of tire rubber, cement, silica fume (SF), fine aggregate (FA), coarse aggregate (CA), and water content. The output of study is the 28 days compressive strength. In this study, Response Surface Methodology will be applied and regression analysis will be conducted on the strength index plot of the data to analyse the inflence of tire rubber replacement on concrete strength in greater details.

Table 2. Data set from literature

\begin{tabular}{ccccccccc}
\hline Source & No. & $\begin{array}{c}\text { Cement } \\
\left(\mathrm{kg} / \mathrm{m}^{3}\right)\end{array}$ & $\begin{array}{c}\mathrm{SF} \\
\left(\mathrm{kg} / \mathrm{m}^{3}\right)\end{array}$ & $\begin{array}{c}\mathrm{CA} \\
\left(\mathrm{kg} / \mathrm{m}^{3}\right)\end{array}$ & $\begin{array}{c}\mathrm{FA} \\
\left(\mathrm{kg} / \mathrm{m}^{3}\right)\end{array}$ & $\begin{array}{c}\text { Water } \\
\left(\mathrm{kg} / \mathrm{m}^{3}\right)\end{array}$ & $\begin{array}{c}\text { Rubber } \\
(\%)\end{array}$ & $\begin{array}{c}\text { Rubber } \\
\text { Size }(\mathrm{mm})\end{array}$ \\
\hline \multirow{2}{*}{ Silva et al. [14] } & 1 & 434 & 43.4 & 1002.5 & 875.2 & 152 & 7.5 & 4.8 \\
& 2 & 434 & 43.4 & 1002.5 & 804.2 & 152 & 15 & 4.8 \\
& 3 & 434 & 43.4 & 1002.5 & 662.3 & 152 & 30 & 4.8 \\
\hline
\end{tabular}


Table 2. Data set from literature (cont.)

\begin{tabular}{|c|c|c|c|c|c|c|c|c|}
\hline Source & No. & $\begin{array}{l}\text { Cement } \\
\left(\mathrm{kg} / \mathrm{m}^{3}\right)\end{array}$ & $\begin{array}{c}\mathrm{SF} \\
\left(\mathrm{kg} / \mathrm{m}^{3}\right)\end{array}$ & $\underset{\left(\mathrm{kg} / \mathrm{m}^{3}\right)}{\mathrm{CA}}$ & $\underset{\left(\mathrm{kg} / \mathrm{m}^{3}\right)}{\mathrm{FA}}$ & $\begin{array}{l}\text { Water } \\
\left(\mathrm{kg} / \mathrm{m}^{3}\right)\end{array}$ & $\begin{array}{l}\text { Rubber } \\
(\%)\end{array}$ & $\begin{array}{c}\text { Rubber } \\
\text { Size }(\mathrm{mm})\end{array}$ \\
\hline \multirow{3}{*}{$\begin{array}{c}\text { Azevedo et al. } \\
\text { [15] }\end{array}$} & 4 & 500 & 0 & 430 & 1193 & 174 & 5 & 2.4 \\
\hline & 5 & 500 & 0 & 430 & 1130 & 174 & 10 & 2.4 \\
\hline & 6 & 500 & 0 & 430 & 1068 & 174 & 15 & 2.4 \\
\hline \multirow{8}{*}{ Elchalakani [13] } & 7 & 380 & 0 & 1040 & 738 & 152 & 10 & 4.0 \\
\hline & 8 & 380 & 0 & 1040 & 656 & 152 & 20 & 4.0 \\
\hline & 9 & 380 & 0 & 1040 & 574 & 152 & 30 & 4.0 \\
\hline & 10 & 380 & 0 & 1040 & 492 & 152 & 40 & 4.0 \\
\hline & 11 & 440 & 44 & 1040 & 738 & 128 & 10 & 4.0 \\
\hline & 12 & 440 & 44 & 1040 & 656 & 128 & 20 & 4.0 \\
\hline & 13 & 440 & 44 & 1040 & 574 & 128 & 30 & 4.0 \\
\hline & 14 & 440 & 44 & 1040 & 492 & 128 & 40 & 4.0 \\
\hline \multirow{3}{*}{ Su et al. [26] } & 15 & 627 & 0 & 1005 & 416 & 232 & 20 & 3.0 \\
\hline & 16 & 621 & 0 & 996 & 410 & 230 & 20 & 0.5 \\
\hline & 17 & 621 & 0 & 996 & 410 & 230 & 20 & 0.3 \\
\hline \multirow{16}{*}{ Gerges et al. [27] } & 18 & 316.8 & 0 & 874.9 & 506.5 & 163.2 & 5 & 1.0 \\
\hline & 19 & 316.8 & 0 & 874.9 & 479.9 & 163.2 & 10 & 1.0 \\
\hline & 20 & 316.8 & 0 & 874.9 & 453.2 & 163.2 & 15 & 1.0 \\
\hline & 21 & 316.8 & 0 & 874.9 & 426.6 & 163.2 & 20 & 1.0 \\
\hline & 22 & 348.4 & 0 & 875 & 476.1 & 163.7 & 5 & 1.0 \\
\hline & 23 & 348.4 & 0 & 875 & 451.1 & 163.7 & 10 & 1.0 \\
\hline & 24 & 348.4 & 0 & 875 & 426 & 163.7 & 15 & 1.0 \\
\hline & 25 & 348.4 & 0 & 875 & 401 & 163.7 & 20 & 1.0 \\
\hline & 26 & 387.1 & 0 & 874.9 & 438.8 & 164.3 & 5 & 1.0 \\
\hline & 27 & 387.1 & 0 & 874.9 & 415.7 & 164.3 & 10 & 1.0 \\
\hline & 28 & 387.1 & 0 & 874.9 & 392.6 & 164.3 & 15 & 1.0 \\
\hline & 29 & 387.1 & 0 & 874.9 & 369.5 & 164.3 & 20 & 1.0 \\
\hline & 30 & 435.5 & 0 & 875 & 438.8 & 165.1 & 5 & 1.0 \\
\hline & 31 & 435.5 & 0 & 875 & 415.7 & 165.1 & 10 & 1.0 \\
\hline & 32 & 435.5 & 0 & 875 & 392.6 & 165.1 & 15 & 1.0 \\
\hline & 33 & 435.5 & 0 & 875 & 369.5 & 165.1 & 20 & 1.0 \\
\hline
\end{tabular}

\section{Response Surface Methodology}

Response Surface Methodology (RSM) is a statistical and mathematical analysis tools which expresses and predicts the dependent variable from multiple predictors. RSM considers the quadratic relation between each predictor to the dependent variable as well as the interaction effect between every predictor with one another. While RSM requires data to be collected in a specific level [20,29], unorganised data gathered from various literature can be analysed by conducting uncoded analysis. RSM also expresses the effect of any chosen two predictors to the dependent variable in contour plot, which is widely used to analyse the influence of a certain factor as presented in building design code such as the Eurocode 2 [30]. 33 data from five studies are used in RSM analysis, and the range of variables is as shown in Table 3. Minitab18 is the software used for the process. The model is evaluated based on the determination coefficient $\left(\mathrm{R}^{2}\right)$ and root meansquare error (RMSE). Supplimentary figures such as the Patero Chart, residual plot, and interaction plot and deviation 
plot provide more information of the model. Lastly, the contour plot is prepared to investigate the impact of rubber tire replacement on the compressive strength on concrete.

Table 3. Range of RSM variables

\begin{tabular}{ccc}
\hline Variable & Lower Bound & Upper Bound \\
\hline Cement $\left(\mathrm{kg} / \mathrm{m}^{3}\right)$ & 316.8 & 500 \\
Silica fume $\left(\mathrm{kg} / \mathrm{m}^{3}\right)$ & 0 & 44 \\
Coarse aggregate $\left(\mathrm{kg} / \mathrm{m}^{3}\right)$ & 430 & 1040 \\
Fine aggregate $\left(\mathrm{kg} / \mathrm{m}^{3}\right)$ & 369.5 & 1193 \\
Water $\left(\mathrm{kg} / \mathrm{m}^{3}\right)$ & 128 & 232 \\
Rubber $(\%)$ & 5 & 40 \\
Rubber size $(\mathrm{mm})$ & 0.30 & 4.80 \\
\hline
\end{tabular}

\section{Regression Analysis}

Regression analysis is performed on the Strength Activity Index (SAI) of rubberised concrete. The expression of SAI is given as:

$$
S A I=\frac{C S_{R \%}}{C S_{0 \%}}
$$

where Index $\mathrm{R}_{\mathrm{R}}$ is the strength index for concrete with $\mathrm{R} \%$ rubber crumb replacement, $\mathrm{CS}_{\mathrm{R}} \%$ is the compressive strength of concrete with $\mathrm{R} \%$ rubber crumb replacement and $\mathrm{CS}_{0 \%}$ is the compressive strength of control specimen for that particular experiment where no tire rubber replacement is being introduced. The strength index allows researcher to study the percentage changes in strength when a replacement material is used. An index of 1.0 indicates the same strength as control specimen, while an index above 1.0 indicates strength gain and vice versa. The strength index is taken as the dependent variable while percentages of rubber replacement is set as the independent variable. The relationship between the variables are determined with correlation and regression analysis.

\section{RESULTS}

\section{Response Surface Methodology}

Response Surface Methodology (RSM) is used to conduct statistical analysis on the strength of rubberised concrete. In the study, stepwise selection of terms is used with $\alpha=0.05$ for both the entering and removing of terms. Uncodded design is used in the analysis as the data obtained from literature will not adhere to the requirement of the generic experiment design. Table 3 shows the RSM regression model produced from the analysis. All the factors in the model have an insignificantly small P-value, indicating the significance of each factors in determining the compressive strength of concrete. Water content of the mix design has a P-value of 0.108 , which is slightly higher than expected but is still sufficiently significant to be included in the final model. The coefficient of determination $\left(\mathrm{R}^{2}\right)$ of the model is 0.9923 , which indicates that $99.23 \%$ of variation in compressive strength can be explained by the set of indepandant variables. The mean square error (RMSE) of the model is 2.368, indicating that the error of data is minimal.

The Pareto chart is shown in Figure 1. The coded terms in the software is automatically assigned as A (cement), B (silica fume), C (coarse aggregate), D (fine aggregate), E (water), F (percentage of rubber replacement) and F (size of tire rubber). From Figure 1, it is shown that the primary constituents of the concrete mix such as silica fume, cement, fine aggregate, and water are significant to the compressive strength of concrete. The exception is coarse aggregate, which is not included in the final model. The addition of silica fume understandably impacts the strength of concrete as it is a pozzolanic material which enhances concrete performance [31]. Rubber replacement is shown to be the second-most significant factor, which fits the term of this study. However, the maximum size of rubber particle used is deemed insignificant. This may happen because the inflence of particle size is less significant compared to the proportion of primary concrete constitutents and the percentage of rubber replacement. While the relationship between particle size and strength exists [26], there is currently insufficient data concerning the effect of particle size to concrete strength. Next, the term AA and FF indicates that the proportion of cement and percentage of rubber replacement affects the strength of concrete in a nonlinear function. Three interaction terms, DE, AF, and BF round up the model. The equation of the model is:

$$
\begin{aligned}
\mathrm{CS}_{28}=-565+ & 0.87 \mathrm{~A}+0.48 \mathrm{~B}+0.52 \mathrm{D}+2.34 \mathrm{E}+1.67 \mathrm{~F}-0.01 \mathrm{~A}^{2}+0.23 \mathrm{~F}^{2}-0.01 \mathrm{AF}+0.01 \mathrm{BF} \\
& -0.003 \mathrm{DE}
\end{aligned}
$$


Figure 2 shows the residual-versus-order plot of the model. The plot is used to identify the existent of other variables not accounted in the modelling. Under normal condition, the residual of the model is distributed randomly. However, exclusion of a significant variable will result in a pattern or trend in the plot. In the model, the residual-versus-order plot shows a random, zig-zag pattern across the data, indicating that there is no unaccounted factor that may impact the model in a significant manner. Figure 3 shows the residual normal probability plot of RSM model. The normality of residual is tested in order to check for the presence or influence of outlier which might affect the accuracy of the model. From the graph, it is clear that most of the points fall close to the normal line except for which stray slightly further around the left end of the graph. Hence, it is verified that there is no outlier that may significantly affect the model's accuracy.

Table 3. RSM regression model

\begin{tabular}{|c|c|c|c|c|c|}
\hline Source & $\mathrm{DF}$ & Adj SS & Adj MS & F-Value & P-Value \\
\hline Model & 10 & 10064.7 & 1006.47 & 283.37 & 0.000 \\
\hline Linear & 5 & 2276.5 & 455.29 & 128.18 & 0.000 \\
\hline Cement & 1 & 98.3 & 98.25 & 27.66 & 0.000 \\
\hline Silica & 1 & 863.1 & 863.06 & 242.99 & 0.000 \\
\hline FA & 1 & 209.0 & 208.98 & 58.84 & 0.000 \\
\hline Water & 1 & 10.0 & 9.97 & 2.81 & 0.108 \\
\hline Rubber $\%$ & 1 & 402.7 & 402.72 & 113.38 & 0.000 \\
\hline Square & 2 & 351.8 & 175.88 & 49.52 & 0.000 \\
\hline Cement*Cement & 1 & 234.5 & 234.45 & 66.01 & 0.000 \\
\hline Rubber $\% *$ Rubber $\%$ & 1 & 151.3 & 151.29 & 42.59 & 0.000 \\
\hline 2-Way Interaction & 3 & 830.4 & 276.81 & 77.94 & 0.000 \\
\hline Cement*Rubber $\%$ & 1 & 113.5 & 113.50 & 31.95 & 0.000 \\
\hline Silica*Rubber $\%$ & 1 & 27.4 & 27.43 & 7.72 & 0.011 \\
\hline FA*Water & 1 & 382.5 & 382.47 & 107.68 & 0.000 \\
\hline Error & 22 & 78.1 & 3.55 & & \\
\hline Total & 32 & 10142.9 & & & \\
\hline RMSE & 2.368 & & & & \\
\hline $\mathrm{R}^{2}$ & 0.9923 & & & & \\
\hline $\mathrm{R}^{2}$ adj & 0.9888 & & & & \\
\hline
\end{tabular}

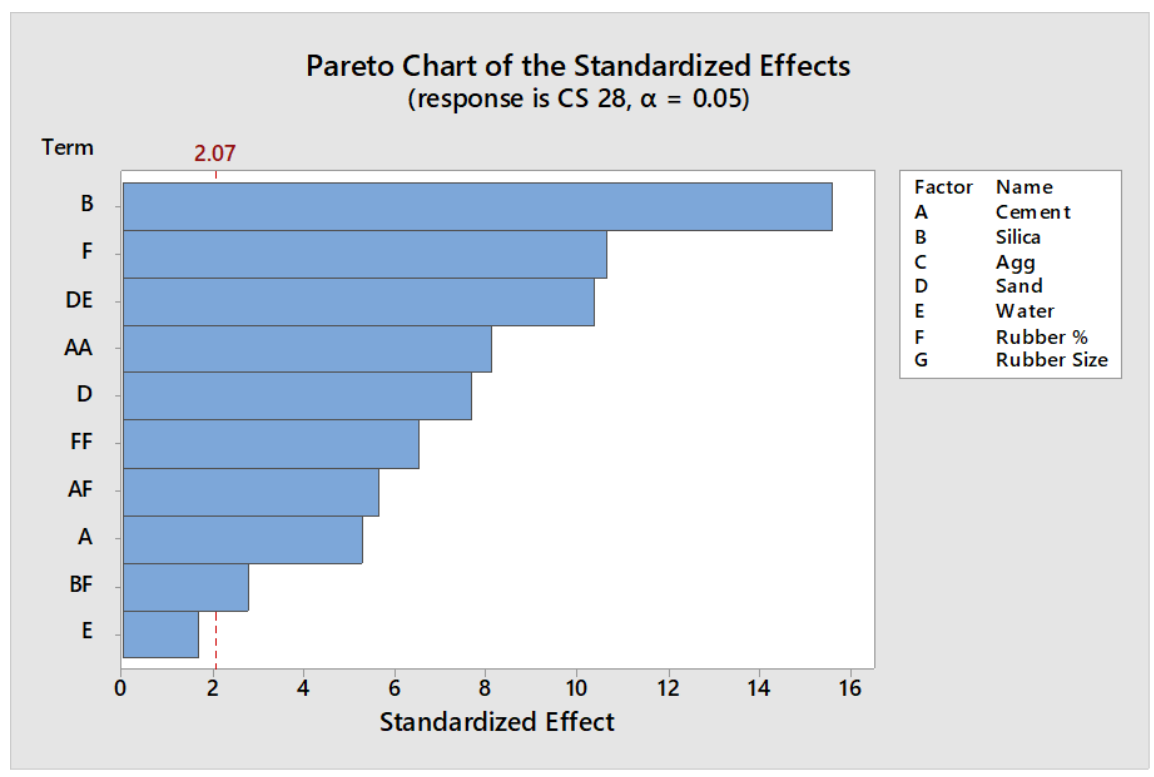

Figure 1. Pareto chart of RSM model 


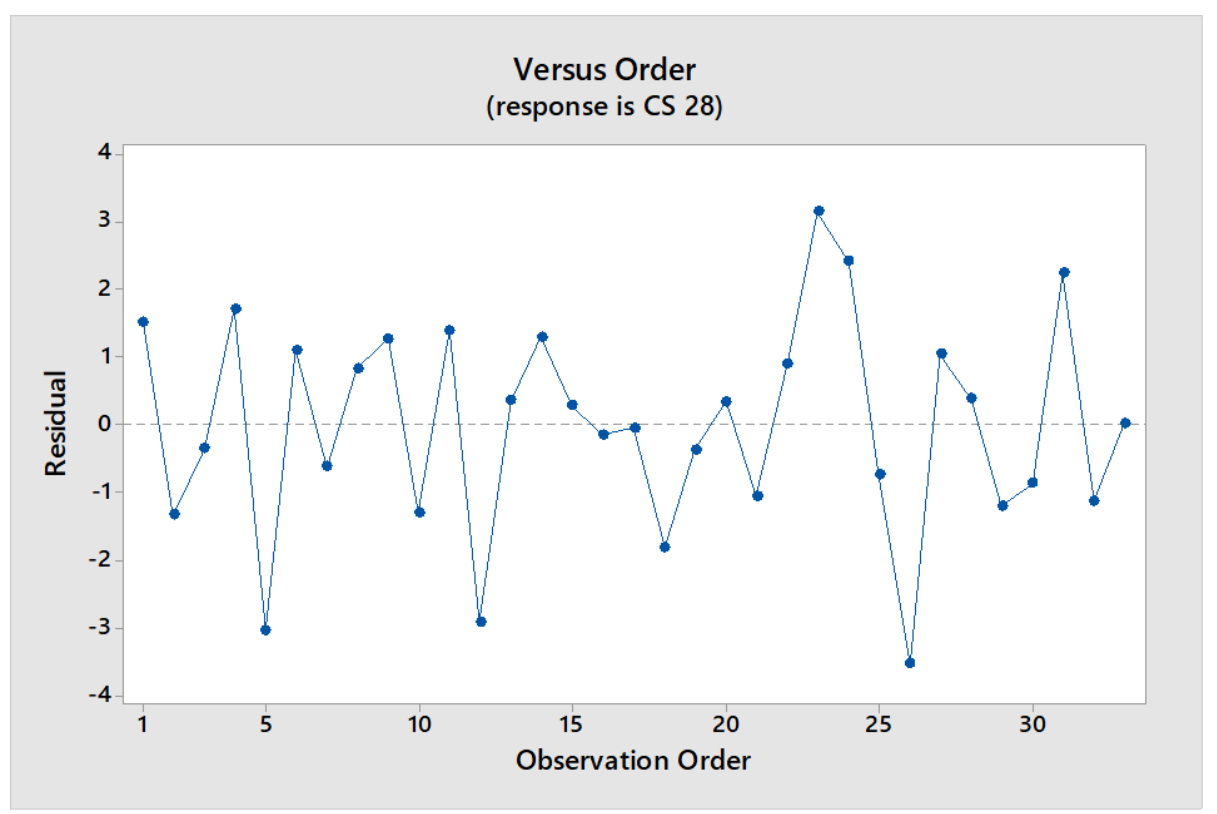

Figure 2. Residual versus order plot of RSM model

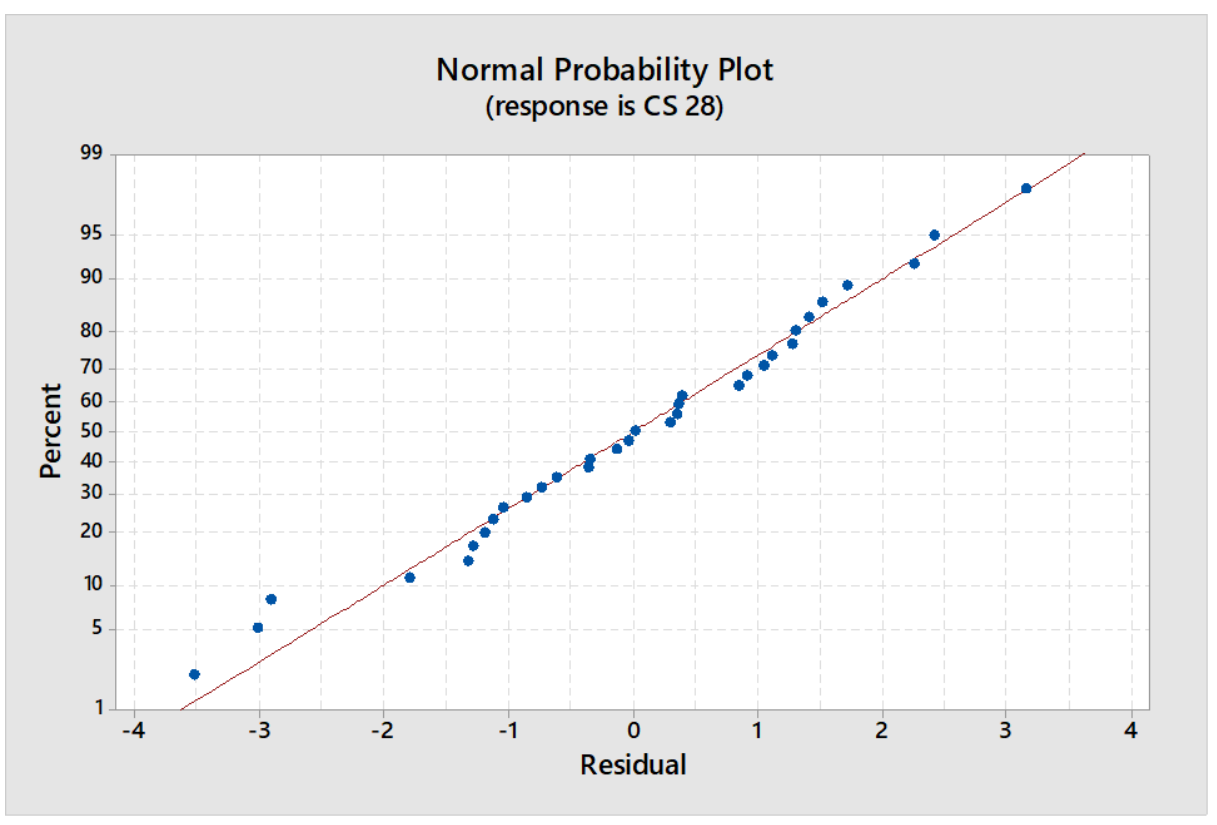

Figure 3. Residual normal probability plot of RSM model

The interaction plot of the model is presented on Figure 4. The interaction plot shows how every significant variable in the model affects the compressive strength of rubberised concrete. The cement content in the mix shows a parabolic curve with respect to compressive strength, with the optimal amount of cement peaked at approximately $450 \mathrm{~kg} / \mathrm{m}^{3}$. Addition of silica fume is beneficial to the strength of concrete, while excessive amount of fine aggregate (sand) negatively affects strength. Compressive strength of concrete also drops when more water is introduced, which agrees with the basic principle of concrete mix design that a higher water-cement ratio produces weaker concrete [32]. Lastly, the percentage of rubber replacement shows a steep downward curve with respect to compressive strength of concrete. This verifies the terms in Pareto chart that the effect of waste tire rubber replacement on strength is not linear. Moreover, the steepness of the curve indicates significant change in compressive strength. Contour plot of RSM model is presented in Figure 5. In the contour plot, the optimum amount of cement is $471.9 \mathrm{~kg} / \mathrm{m}^{3} .47 .2 \mathrm{~km} / \mathrm{m}^{3}$ of silica fume, accounting for $10 \%$ mass of cement, is used, and the amount of sand is $801.25 \mathrm{~kg} / \mathrm{m}^{3}$. Based on the aforementioned setting, the effect of tire rubber is clearly shown by the change in contour in different percentage of replacement, which indicate significant reduction of compressive strength with percentage of replacement. The diagonal pattern of each contour line is caused by the effect of water content, which reduces strength with more water. 


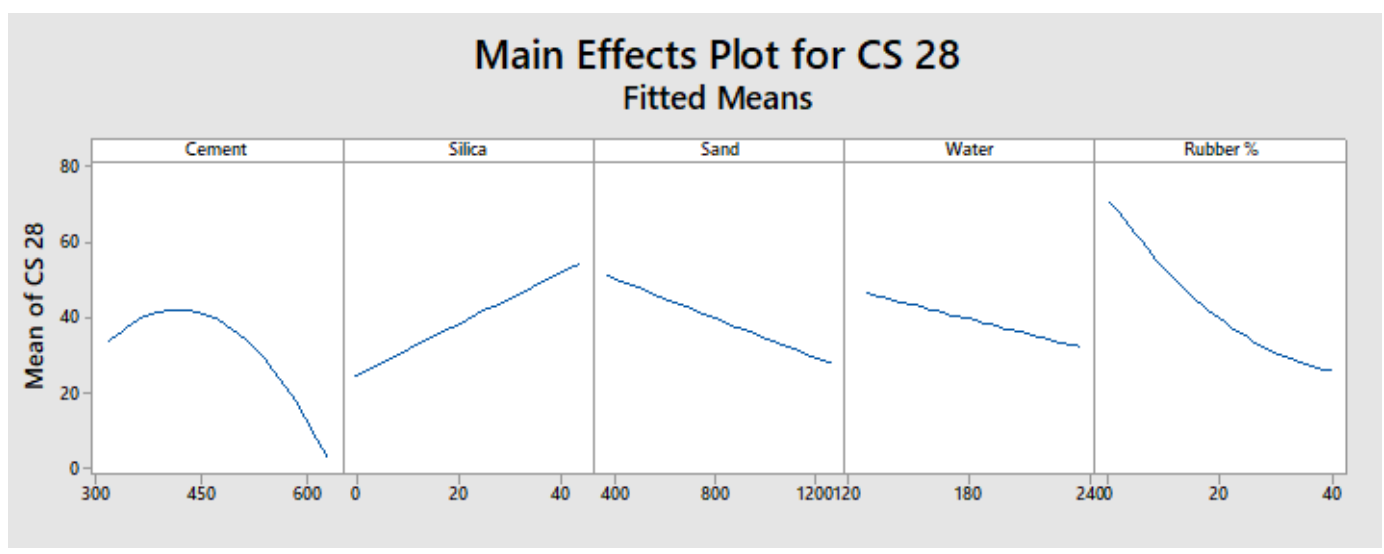

Figure 4. Interaction plot of RSM model

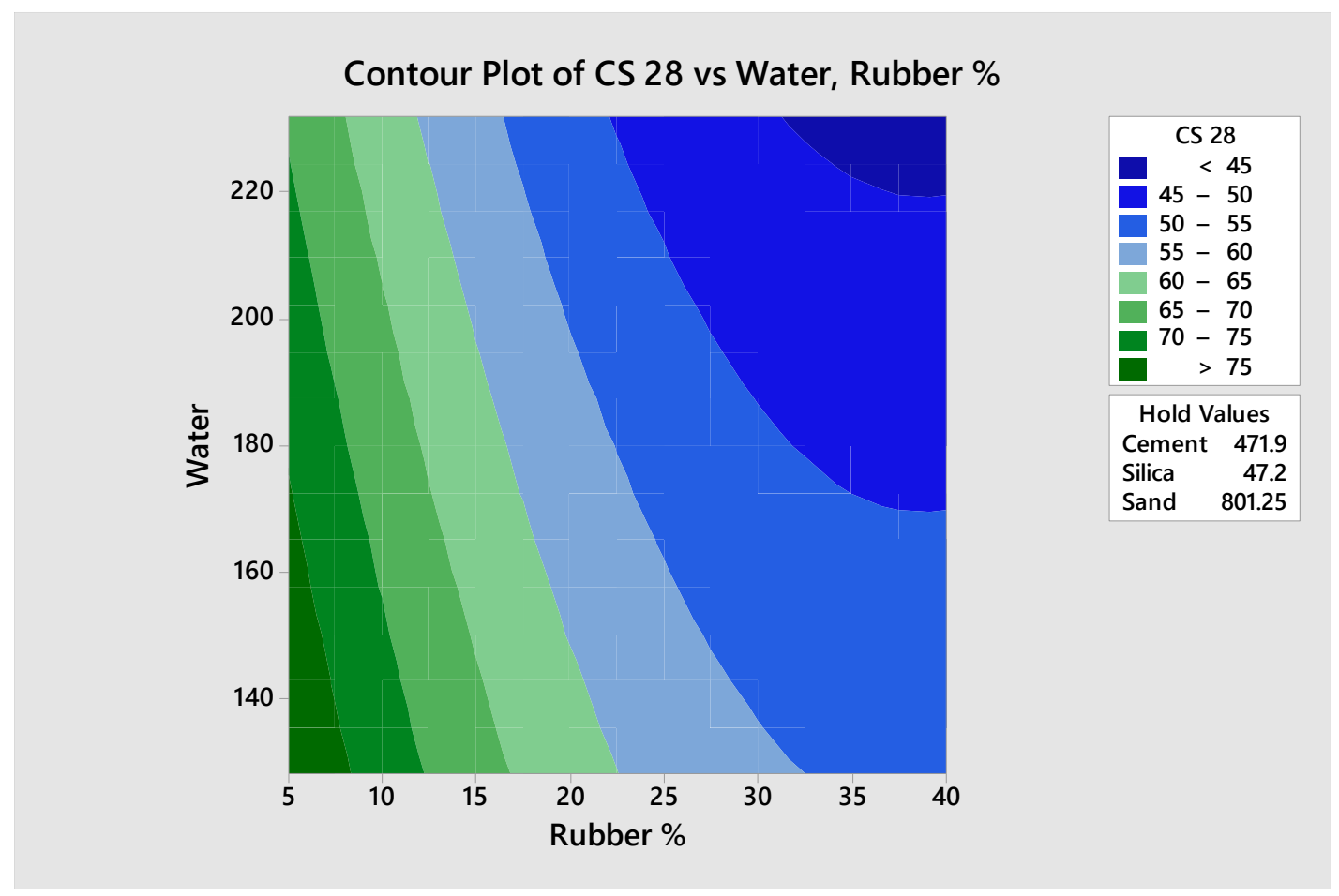

Figure 5. Contour plot of RSM model

To further evaluate if the deviation of data falls into an accetable range, the a-10 index is adopted [33]. Originally proposed as a-20 index for the evaluation of Articial Neural Network (ANN) model, this parameter can be applied similarly to other prediction models. The purpose of the index is to evaluate the accuracy of the model by studying the margin of error between the predicted value and actual value. The expression of the a-10 index is;

$$
a-10 \text { index }=\frac{M_{10}}{M}
$$

where $\mathrm{M}_{10}$ is the number of samples in which the ratio of predicted value and actual value falls within the range of 0.90 to 1.10 and $\mathrm{M}$ is total number of experiment sets. In short, the a-10 index measures the percentage of data with deviation within $\pm 10 \%$. The experimental value and predicted value from RSM model is plotted on a graph as shown in Figure 6 . Two boundary lines, namely the $y=1.10 x$ axis and $y=0.90 x$ axis serves as the range for $\pm 10 \%$ deviation. A data point is within the $\pm 10 \%$ deviation when it falls within the constrain of the red zone. Using the same concept, the a-20 index can also be used to determine the percentages of data point within $\pm 20 \%$ margin of error. It can be seen that a majority of the data points fall within the zone of minimal error. However, a few data points, particularly from mix design with compressive strength below 30MPa shows slightly huge deviation. The experimental and predicted value, as well as the deviation is tabulated on Table 4. From the calculation, the a-10 index and a-20 index of the model are 0.789 and 0.970 
respectively. Hence, $78.9 \%$ of the prediction falls within $\pm 10 \%$ deviation and all but one data point (32 out of 33 ) are within $\pm 20 \%$ deviation. It can then be concluded that the RSM model is highly reliable and accurate.

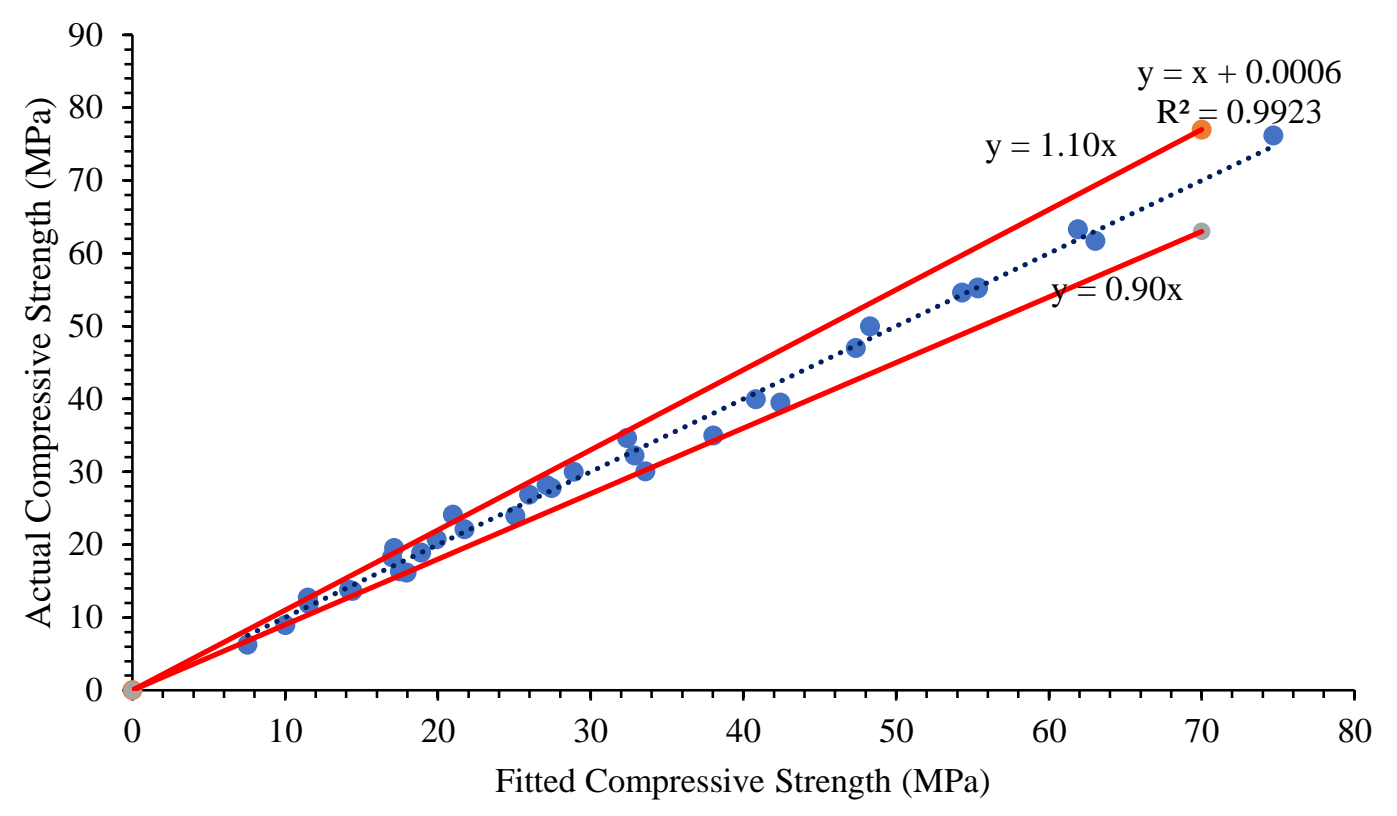

Figure 6. Actual versus predicted compressive strength plot

Table 4. Experimental and predicted value of RSM model

\begin{tabular}{|c|c|c|c|c|}
\hline No. & Experimental & Predicted & Residual & Deviation (\%) \\
\hline 1 & 76.2 & 74.68 & 1.52 & 1.99 \\
\hline 2 & 61.7 & 63.03 & -1.33 & -2.16 \\
\hline 3 & 47 & 47.35 & -0.35 & -0.74 \\
\hline 4 & 50 & 48.28 & 1.72 & 3.44 \\
\hline 5 & 35 & 38.02 & -3.02 & -8.63 \\
\hline 6 & 30 & 28.89 & 1.11 & 3.70 \\
\hline 7 & 32.25 & 32.87 & -0.62 & -1.92 \\
\hline 8 & 20.75 & 19.91 & 0.84 & 4.05 \\
\hline 9 & 12.75 & 11.47 & 1.28 & 10.04 \\
\hline 10 & 6.25 & 7.54 & -1.29 & -20.64 \\
\hline 11 & 63.3 & 61.89 & 1.41 & 2.23 \\
\hline 12 & 39.5 & 42.41 & -2.91 & -7.37 \\
\hline 13 & 27.8 & 27.44 & 0.36 & 1.29 \\
\hline 14 & 18.3 & 16.99 & 1.31 & 7.16 \\
\hline 15 & 54.6 & 54.31 & 0.29 & 0.53 \\
\hline 16 & 55.2 & 55.34 & -0.14 & -0.25 \\
\hline 17 & 55.3 & 55.34 & -0.04 & -0.07 \\
\hline 18 & 16.15 & 17.95 & -1.80 & -11.15 \\
\hline 19 & 13.82 & 14.18 & -0.36 & -2.60 \\
\hline 20 & 11.88 & 11.53 & 0.35 & 2.95 \\
\hline
\end{tabular}


Table 4. Experimental and predicted value of RSM model (cont.)

\begin{tabular}{ccccc}
\hline No. & Experimental & Predicted & Residual & Deviation $(\%)$ \\
\hline 21 & 8.97 & 10.02 & -1.05 & -11.71 \\
22 & 26.88 & 25.97 & 0.91 & 3.39 \\
23 & 24.13 & 20.98 & 3.15 & 13.05 \\
24 & 19.53 & 17.12 & 2.41 & 12.34 \\
25 & 13.65 & 14.39 & -0.74 & -5.42 \\
26 & 30.07 & 33.59 & -3.52 & -11.71 \\
27 & 28.15 & 27.1 & 1.05 & 3.73 \\
28 & 22.13 & 21.74 & 0.39 & 1.76 \\
29 & 16.31 & 17.51 & -1.20 & -7.36 \\
30 & 39.95 & 40.81 & -0.86 & -2.15 \\
31 & 34.63 & 32.38 & 2.25 & 6.50 \\
32 & 23.96 & 25.08 & -1.12 & -4.67 \\
33 & 18.93 & 18.91 & 0.02 & 0.11 \\
\hline a-10 index & 0.789 & & & \\
a-20 index & 0.970 & & & \\
\hline
\end{tabular}

\section{Regression Analysis}

Regression analysis is performed on the strength index of concrete compression strength with respect to the control mix of the respective experiment in which no rubber replacement has been done. The strength index of the literature is plotted on Figure 7. Linear, second-order polynomial, and exponential regression are attempted to derive an expression for the compressive strength index of concrete with varying percentages of waste tire rubber replacement. The intercept is forced to be 1.0 as the strength index of control concrete without tire rubber replacement is always 1.0. The coefficient of determination and expression of each relationship is tabulated on Table 4. From the table, linear expression has a R2 value of 0.6299 which is not satisfactory as RSM analysis has also indicated that the relationship between strength and rubber replacement is not linear in nature. Second-order polynomial or quadratic expression has R2 value of 0.6456 . Both expressions are moderately correlated $(\mathrm{R} 2>0.60)$ with the strength index of rubberised concrete. However, exponential expression achieves $\mathrm{R} 2$ value of 0.8719 , which indicate that about $87 \%$ of the variance in the data can be explained by the percentage of rubber replacement. This means that the strength index of rubberised concrete has a strong exponential correlation $(\mathrm{R} 2>0.80)$ with percentage of rubber replacement. The significant reduction in compressive strength is attributed to a few reasons. First, compared to conventional fine aggregate, rubber particles form weaker bonds with cement paste. This leads to a weakness at the interfacial transition zone (ITZ) and compromises the internal structure of concrete [34]. Next, rubber particle has a weaker load-bearing capacity compared to fine aggregate [35]. Lastly, the soft and elastical morphology of rubber particle is detriminal to concrete strength. With that, the reduction of concrete strength with waste tire rubber as fine aggregate replacement occurs in an exponential function. 


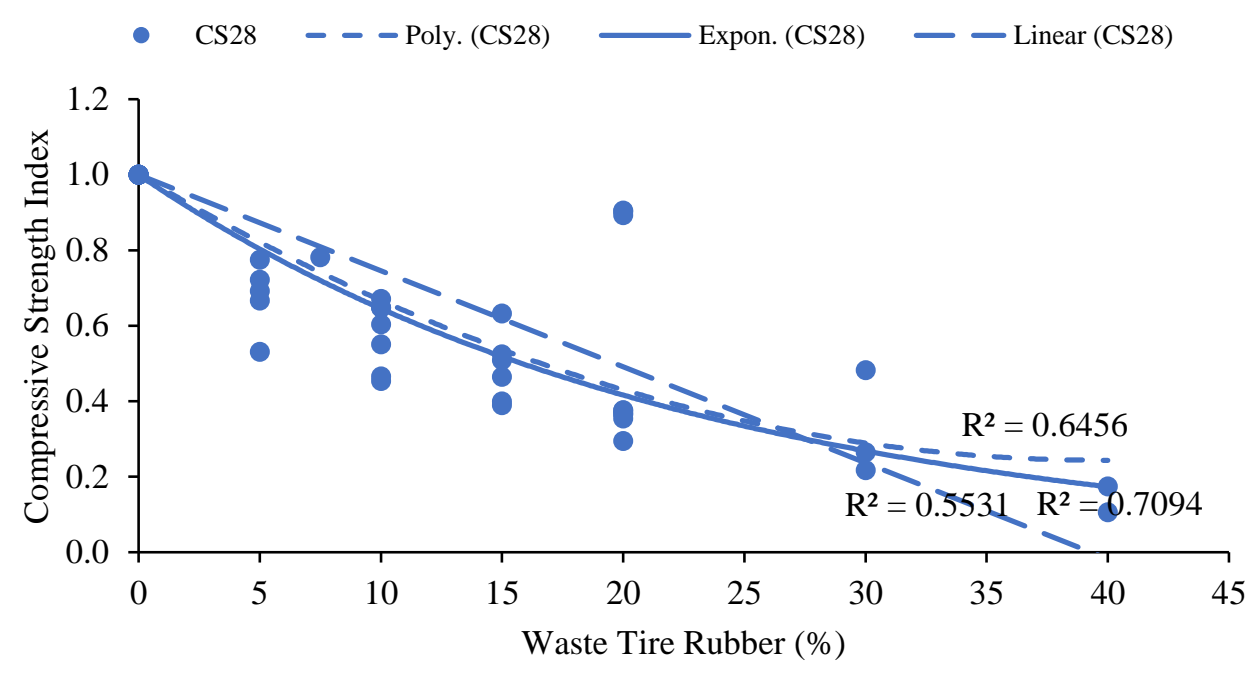

Figure 7. Strength index of rubberised concrete

Table 4. Expression of rubberised concrete strength index

\begin{tabular}{ccc}
\hline Regression & $\mathrm{R}^{2}$ & Expression \\
\hline Linear & 0.6299 & $\mathrm{y}=-0.0254 \mathrm{x}+1$ \\
Exponential & 0.8719 & $\mathrm{y}=\mathrm{e}^{-0.044 \mathrm{x}}$ \\
Second-order Polynomial & 0.6456 & $\mathrm{y}=0.0005 \mathrm{x}^{2}-0.038 \mathrm{x}+1$ \\
\hline
\end{tabular}

\section{CONCLUSIONS}

In the present study, the 28 days compressive strength of concrete with waste tire rubber as sand replacement is modelled using RSM. 33 data sets from five literature are selected for the analysis. Seven input variables which comprises the proportion of concrete constituent materials as well as the percentage of rubber replacement and maximum size of rubber particle are selected as the predictors of the study. RSM model accurately products a model for the prediction of rubberised concrete strength even though the proportion of coarse aggregate and rubber size are excluded from the model. Cement and silica has favorable effect on concrete strength while increased water-cement ratio reduces the strength of concrete. At the same time, a steep download curve on the main effect plot indicates significant strength reduction with percentage of rubber replacement. The resulting model has $\mathrm{R}^{2}$ value of $99.23 \%$, RMSE of 2.368 , and the predicted value falls within the acceptable margin of error. Strength index of rubberised concrete mixes are calculated from the ratio between the strength of control concrete and rubberised concrete. Regression analysis is carried out on the compilation of strength index and it is concluded that the strength of rubberised concrete is most suitably expressed in an exponential function with respect to the percentage of rubber replacement. The reduction occurs due to the morphology of rubber particle and the inability of rubber particle to form strong bond with cement paste and other concrete constituents. Hence, pre-treatment of rubber is strongly adviced to recover some strength of concrete. In addition, replacement portion of fine aggregate with tire rubber should be limited or addition of rubber into concrete may be instead conducted to minimise the strength loss of concrete. This study provides a heightened understanding of rubberised concrete strength prediction and behaviour.

\section{ACKNOWLEDGMENTS}

This research was supported by Universiti Malaysia Pahang under grant number PGRS200370 Properties of High Strength Concrete with Eggshell as Partial Cement Replacement and Tire Crumb as Sand Replacement.

\section{REFERENCES}

[1] A. Hejna, J. Korol, M. Przybysz-Romatowska, Ł. Zedler, B. Chmielnicki, and K. Formela, "Waste tire rubber as low-cost and environmentally-friendly modifier in thermoset polymers - A review," Waste Manag., vol. 108, no. 2020, pp. 106-118, 2020, doi: 10.1016/j.wasman.2020.04.032. 
[2] J. D. Martínez, N. Puy, R. Murillo, T. García, M. V. Navarro, and A. M. Mastral, "Waste tyre pyrolysis - A review," Renew. Sustain. Energy Rev., vol. 23, pp. 179-213, 2013, doi: 10.1016/j.rser.2013.02.038.

[3] W. H. Yung, L. C. Yung, and L. H. Hua, "A study of the durability properties of waste tire rubber applied to self-compacting concrete," Constr. Build. Mater., vol. 41, pp. 665-672, 2013, doi: 10.1016/j.conbuildmat.2012.11.019.

[4] F. Moreno, M. C. Rubio, and M. J. Martinez-Echevarria, "Use of crumb rubber in flexible pavements," Int. J. Innov. Res. Sci. Technol., no. February, pp. 1-8, 2018, doi: 10.15680/IJIRSET.2018.0704009.

[5] A. Benazzouk, O. Douzane, T. Langlet, K. Mezreb, J. M. Roucoult, and M. Quéneudec, "Physico-mechanical properties and water absorption of cement composite containing shredded rubber wastes," Cem. Concr. Compos., vol. 29, no. 10, pp. 732740, 2007, doi: 10.1016/j.cemconcomp.2007.07.001.

[6] S. K. Thiruvangodan, "Waste Tyre Management in Malaysia," Universiti Putra Malaysia, 2006.

[7] V. Munikanan, M. A. Yahya, M. A. Yusof, and M. H. F. Radzi, "Fine granular of shredded waste tyre for road kerb application as improvised road furniture," in International Conference On Engineering And Technology (Intcet 2017), 2018, p. 020061, doi: 10.1063/1.5022955.

[8] M. J. Forrest, "Recycling and Re-use of Waste Rubber," in Recycling and Re-use of Waste Rubber, no. July, 2019.

[9] A. H. Buss, J. L. Kovaleski, R. N. Pagani, V. L. da Silva, and J. de Matos Silva, "Proposal to Reuse Rubber Waste from EndOf-Life Tires Using Thermosetting Resin," Sustain., vol. 11, no. 24, 2019, doi: 10.3390/su11246997.

[10] A. Moustafa and M. A. Elgawady, "Mechanical properties of high strength concrete with scrap tire rubber," Constr. Build. Mater., vol. 93, pp. 249-256, 2015, doi: 10.1016/j.conbuildmat.2015.05.115.

[11] N. H. Deshmukh and P. D. Y. Kshirsagar, "Utilization of rubber waste in construction of flexible pavement," Int. J. Adv. Res. Dev., vol. 2, no. 7, pp. 70-77, 2017, [Online]. Available: www.ijarnd.com.

[12] K. A. Bani-Hani and A. Senouci, "Using waste tire crumb rubber as an alternative aggregate for concrete pedestrian blocks," Jordan J. Civ. Eng., vol. 9, no. 3, pp. 400-409, 2015, doi: 10.14525/jjce.9.3.3080.

[13] M. Elchalakani, "High strength rubberized concrete containing silica fume for the construction of sustainable road side barriers," Structures, vol. 1, pp. 20-38, 2015, doi: 10.1016/j.istruc.2014.06.001.

[14] F. M. Silva, E. J. P. Miranda, J. M. C. Dos Santos, L. A. Gachet-Barbosa, A. E. Gomes, and R. C. C. Lintz, "The use of tire rubber in the production of high-performance concrete," Ceramica, vol. 65, pp. 110-114, 2019, doi: 10.1590/03666913201965 S12598.

[15] F. Azevedo, F. Pacheco-Torgal, C. Jesus, J. L. Barroso De Aguiar, and A. F. Camões, "Properties and durability of HPC with tyre rubber wastes," Constr. Build. Mater., vol. 34, pp. 186-191, 2012, doi: 10.1016/j.conbuildmat.2012.02.062.

[16] A. Siddika, M. A. Al Mamun, R. Alyousef, Y. H. M. Amran, F. Aslani, and H. Alabduljabbar, "Properties and utilizations of waste tire rubber in concrete: A review," Constr. Build. Mater., vol. 224, pp. 711-731, Nov. 2019, doi: 10.1016/j.conbuildmat.2019.07.108.

[17] I. H. Boyaci, "A new approach for determination of enzyme kinetic constants using response surface methodology," Biochem. Eng. J., vol. 25, no. 1, pp. 55-62, 2005, doi: 10.1016/j.bej.2005.04.001.

[18] A. Busari, "Response Surface Analysis of the Compressive Strength of Metakoalin Self-Compacting Concrete," Adv. Sci. Technol. Res. J., vol. 13, no. 2, pp. 7-13, 2019, doi: 10.12913/22998624/105608.

[19] de la R. Ángel, G. Ruiz, and E. Poveda, "Study of the Compression Behavior of Steel-Fiber Reinforced Concrete by Means of the Response Surface Methodology,” Appl. Sci., vol. 9, no. 24, p. 5330, Dec. 2019, doi: 10.3390/app9245330.

[20] A. Hammoudi, K. Moussaceb, C. Belebchouche, and F. Dahmoune, "Comparison of artificial neural network (ANN) and response surface methodology (RSM) prediction in compressive strength of recycled concrete aggregates," Constr. Build. Mater., vol. 209, pp. 425-436, 2019, doi: 10.1016/j.conbuildmat.2019.03.119.

[21] B. S. Thomas, R. C. Gupta, P. Mehra, and S. Kumar, "Performance of high strength rubberized concrete in aggressive environment," Constr. Build. Mater., vol. 83, pp. 320-326, 2015, doi: 10.1016/j.conbuildmat.2015.03.012.

[22] B. S. Thomas, R. C. Gupta, and V. J. Panicker, "Recycling of waste tire rubber as aggregate in concrete: Durability-related performance," J. Clean. Prod., vol. 112, pp. 504-513, 2016, doi: 10.1016/j.jclepro.2015.08.046.

[23] G. Girskas and D. Nagrockiené, "Crushed rubber waste impact of concrete basic properties," Constr. Build. Mater., vol. 140, pp. 36-42, 2017, doi: 10.1016/j.conbuildmat.2017.02.107.

[24] A. Abdelmonem, M. S. El-Feky, E. S. A. R. Nasr, and M. Kohail, "Performance of high strength concrete containing recycled rubber," Constr. Build. Mater., vol. 227, p. 116660, 2019, doi: 10.1016/j.conbuildmat.2019.08.041.

[25] N. Ganesan, J. Bharati Raj, and A. P. Shashikala, "Flexural fatigue behavior of self compacting rubberized concrete," Constr. Build. Mater., vol. 44, pp. 7-14, 2013, doi: 10.1016/j.conbuildmat.2013.02.077.

[26] H. Su, J. Yang, T. C. Ling, G. S. Ghataora, and S. Dirar, "Properties of concrete prepared with waste tyre rubber particles of uniform and varying sizes," J. Clean. Prod., vol. 91, no. December, pp. 288-296, 2015, doi: 10.1016/j.jclepro.2014.12.022.

[27] N. N. Gerges, C. A. Issa, and S. A. Fawaz, "Rubber concrete: Mechanical and dynamical properties," Case Stud. Constr. Mater., vol. 9, no. August, p. e00184, 2018, doi: 10.1016/j.cscm.2018.e00184.

[28] K. B. Najim and M. R. Hall, "A review of the fresh/hardened properties and applications for plain- (PRC) and self-compacting rubberised concrete (SCRC)," Constr. Build. Mater., vol. 24, no. 11, pp. 2043-2051, 2010, doi: 10.1016/j.conbuildmat.2010.04.056. 
[29] A. M. Grabiec and Z. Piasta, "Study on compatibility of cement-superplasticiser assisted by multicriteria statistical optimisation,” J. Mater. Process. Technol., vol. 154, pp. 197--2203, 2004, doi: 10.1016/j.matprotec.2004.03.020.

[30] ENV 1992-1 Eurocode 2. Design of Concrete Structures-Part 1: General Rules and Rules for Buildings. London, United Kingdom: British Standards Institution, 2004.

[31] A. Jain, “Characteristics of Silica Fume Concrete,” Int. J. Comput. Appl., pp. 23-26, 2015.

[32] D. Rao and D. T. Sekhar, "Studies on Relationship Between Water/Binder Ratio And Compressive Strength Of High Volume Fly Ash Concrete," Am. J. Eng. Res., vol. 02, no. 08, pp. 2320-847, 2015, [Online]. Available: www.ajer.org.

[33] P. G. Asteris and V. G. Mokos, "Concrete compressive strength using artificial neural networks," Neural Comput. Appl., vol. 32, no. 15, pp. 11807-11826, 2020, doi: 10.1007/s00521-019-04663-2.

[34] C. Nagarajan, P. Shanumugasundaram, and S. R. Anmeeganathan, "Properties of high strength concrete containing surfacemodified crumb rubber," Gradjevinar, vol. 71, no. 7, pp. 579-588, 2019, doi: 10.14256/JCE.2312.2018.

[35] B. S. Thomas and R. Chandra Gupta, "Properties of high strength concrete containing scrap tire rubber," J. Clean. Prod., vol. 113, pp. 86-92, 2016, doi: 10.1016/j.jclepro.2015.11.019. 